\title{
Short Communication \\ The expression of RUNX3 in colorectal cancer is associated with disease stage and patient outcome
}

\author{
R Soong ${ }^{*, 1,2}$, N Shah', BK Peh', PY Chong', SS Ng', N Zeps ${ }^{3,4}$, D Joseph ${ }^{3,4}$, M Salto-Tellez $^{1,2}$, B lacopetta ${ }^{4}$ \\ and $Y$ Ito ${ }^{1,5}$
}

'Oncology Research Institute, Yong Loo Lin School of Medicine, National University of Singapore, Singapore, Singapore; ${ }^{2}$ Department of Pathology, National University of Singapore, Singapore, Singapore; ${ }^{3}$ Department of Radiation Oncology, Sir Charles Gairdner Hospital, Nedlands 6009, Australia; ${ }^{4}$ School of Surgery, The University of Westem Australia, Nedlands 6009, Australia; ${ }^{5}$ Institute of Molecular and Cellular Biology, Proteos, Singapore, Singapore

RUNX3 is believed to have tumour suppressor properties in several cancer types. Inactivation of RUNX3 has been shown to occur by methylation-induced transcriptional silencing and by mislocalization of the protein to the cytoplasm. The aim of this study was to examine the clinical significance of RUNX3 expression in a large series of colorectal cancers using immunohistochemistry and tissue arrays. With advancing tumour stage, expression of RUNX3 in the nucleus decreased, whereas expression restricted to the cytoplasmic compartment increased. Nuclear RUNX3 expression was associated with significantly better patient survival compared to tumours in which the expression of RUNX3 was restricted to the cytoplasm $(P=0.025)$. These results support a role for $R U N X 3$ as a tumour suppressor in colorectal cancer.

British Journal of Cancer (2009) I 00, 676-679. doi:I0.1038/sj.bjc.6604899 www.bjcancer.com

Published online 17 February 2009

(c) 2009 Cancer Research UK

Keywords: RUNX3; colorectal cancer; tissue arrays; prognosis; Wnt

The RUNX3 gene encodes a protein that belongs to the runt domain family of transcription factors involved in mammalian development pathways (Ito, 2008). RUNX3 protein can mediate the growth suppressive effects of TGF- $\beta$ by associating with SMAD, a downstream protein in the signalling pathway (Ito and Miyazono, 2003). In RUNX3 knockout mice, the gastric epithelium displays hyperplasia and a reduced sensitivity to TGF- $\beta$ ( $\mathrm{Li}$ et al, 2002). The chromosomal locus for RUNX3 (1p36) shows frequent loss of heterozygosity in a variety of cancer types including colon and gastric carcinomas (Ito, 2008). In addition, mutations in RUNX3 have been shown in gastric (Li et al, 2002) and bladder (Kim et al, 2005) cancers. Recent work from our group has also shown that RUNX3 protein forms a ternary complex with $\beta$-catenin/TCF4 (Ito et al, 2008). This complex has reduced DNA-binding ability and thus attenuates the level of signalling through the Wnt pathway. The above findings suggest a putative tumour suppressor role for RUNX3 in intestinal tumourigenesis.

Other studies have shown methylation-related transcriptional silencing of RUNX3 expression in gastric (Li et al, 2002; Waki et al, 2003), colorectal (CRC) (Goel et al, 2004; Ku et al, 2004) and oesophageal squamous cell (Sakakura et al, 2007) carcinomas. A relatively high frequency of RUNX3 methylation has also been observed in hepatocellular carcinoma and lung, breast and prostate cancers (Kim et al, 2004). Mislocalisation of RUNX3

* Correspondence: Dr R Soong, Oncology Research Institute, Centre for Life Science Level 2, National University of Singapore, 28 Medical Drive, I I7456, Singapore; E-mail: nmirs@nus.edu.sg

Received 2 October 2008; revised 16 December 2008; accepted 28 December 2008; published online 17 February 2009 protein to the cytoplasm is another mechanism by which RUNX3 can be inactivated in gastric and breast cancers (Ito et al, 2005; Lau et al, 2006). Overexpression of the enhancer of zeste homologue 2 (EZH2) protein was recently shown to downregulate RUNX3 expression by increasing histone $\mathrm{H} 3$ methylation, thus providing yet another mechanism for inactivation of RUNX3 (Fujii et al, 2008). As might be expected, if RUNX3 were behaving as a tumour suppressor, the decreased expression of this protein in gastric (Wei et al, 2005), lung (Araki et al, 2005) and oesophageal (Sakakura et al, 2007) cancers has been associated with worse patient outcome.

As the TGF- $\beta$ signalling pathway plays an important role in the growth control of human colonic epithelial cells (Xu and Pasche, 2007), RUNX3 may also act as a tumour suppressor gene in this tissue. Approximately $20 \%$ of primary CRCs show hypermethylation of RUNX3 (Goel et al, 2004; Ogino et al, 2007), and this has been linked to transcriptional silencing in two studies (Goel et al, 2004; Ku et al, 2004). The high specificity of RUNX3 methylation in tumour tissue relative to normal colonic mucosa has led to its inclusion in a panel of five genes proposed for the standardised classification of the $\mathrm{CpG}$ island methylator phenotype (CIMP) in CRC (Weisenberger et al, 2006). Although it is clear that methylation of the RUNX3 promoter region is one of the ways in which this gene can be inactivated in CRC, other mechanisms including mislocalisation of RUNX3 protein could also be occurring. The expression of RUNX3 in CRC as determined by immunohistochemistry has not previously been reported. In this study, we used tissue microarrays containing a very large number of primary CRC samples to investigate the expression of RUNX3 in relation to tumour features and to patient outcome. 


\section{MATERIALS AND METHODS}

\section{Tissue microarrays}

Sections from tissue microarray (TMA) blocks containing 849 CRC (stages I-IV) and matching normal tissue samples were obtained from the West Australian Research Tissue Network, Department of Radiation Oncology, Sir Charles Gairdner Hospital. Construction of the TMAs and the tumour and patient characteristics have been described elsewhere (Chai et al, 2004). Microsatellite instability (MSI) status was determined using the BAT26 mononucleotide marker as described previously (Chai et al, 2004). Ethics approval to perform this study was obtained from the Human Research Ethics Committee of the Sir Charles Gairdner Hospital.

\section{Immunohistochemistry}

Sections from tissue array blocks were cut at $5 \mu \mathrm{m}$ thickness and stained for RUNX3 by immunohistochemistry using the monoclonal antibody clone R3-6E9 as described previously by our group (Ito et al, 2005). The R3-6E9 clone recognises an epitope within the 191-234 amino-acid region. Its specificity for human RUNX3 has been shown by Western blot analysis and by the removal of immunoreactivity to normal gastric mucosa following preincubation with RUNX3 peptide (Ito et al, 2005). Rehydrated TMA sections were warmed in target retrieval solution (DAKO, Glostrup, Denmark) at $96^{\circ} \mathrm{C}$ for $40 \mathrm{~min}$, treated with a serum-free blocking solution (DAKO), and then incubated overnight at $4{ }^{\circ} \mathrm{C}$ with $1 \mu \mathrm{g} / \mathrm{ml} \mathrm{R} 3-6 \mathrm{E} 9$ in a diluent solution (DAKO). A peroxidase-3, $3^{\prime}$-diaminobenzidine-based detection system (EnVision + kit, DAKO) was used to detect immunoreactivity. Staining was graded for intensity on a scale of $0-4$ in the nuclear and cytoplasmic compartments. The scoring was performed by a single pathologist (NS) following consultation with another pathologist (MST) and in the absence of information on patient outcome or tumour pathology. RUNX3 was considered to be expressed in the nucleus or cytoplasm if the intensity was estimated at $\geqslant 2$.

\section{RESULTS AND DISCUSSION}

Typically observed immunohistochemical staining patterns for RUNX3 are shown in Figure 1. Using a staining intensity of $\geqslant 2$ as the threshold, RUNX3 expression was expressed in the nucleus of $631 / 849(74 \%)$ tumours and in the cytoplasm of $431 / 849(51 \%)$ tumours. Both nuclear and cytoplasmic expressions were present in $352(41 \%)$ tumours, nuclear expression only in $279(33 \%)$, neither nuclear nor cytoplasmic expression in $139(16 \%)$ and cytoplasmic expression only in 79 (9\%) tumours. In this study, tumours with 'any nuclear' staining were considered to express 'active' RUNX3 ( $n=631$, Group A) (Lau et al, 2006). Tumours with no nuclear or cytoplasmic staining (Group B) or with expression in the cytoplasm only (Group C) were considered to have 'inactive' RUNX3.

The associations between RUNX3 expression and clinicopathological and molecular features of the CRC series are shown in Table 1. No significant associations were seen with patient age or gender, or with the histological grade of the tumour. Tumours located in the proximal colon displayed a trend for less frequent expression of nuclear RUNX3 compared to those arising in the distal colon and rectum. A likely explanation for this finding is that CIMP + and RUNX3 methylation are known to occur more often in the proximal colon (Weisenberger et al, 2006) and are associated with methylation-induced transcriptional silencing. The MSI + phenotype is also closely associated with the CIMP + phenotype, thus accounting for the lower frequency of nuclear RUNX3 expression observed in MSI + tumours (Table 1).

In keeping with its postulated role as a tumour suppressor, advanced stage tumours (AJCC stages III and IV) showed less
A

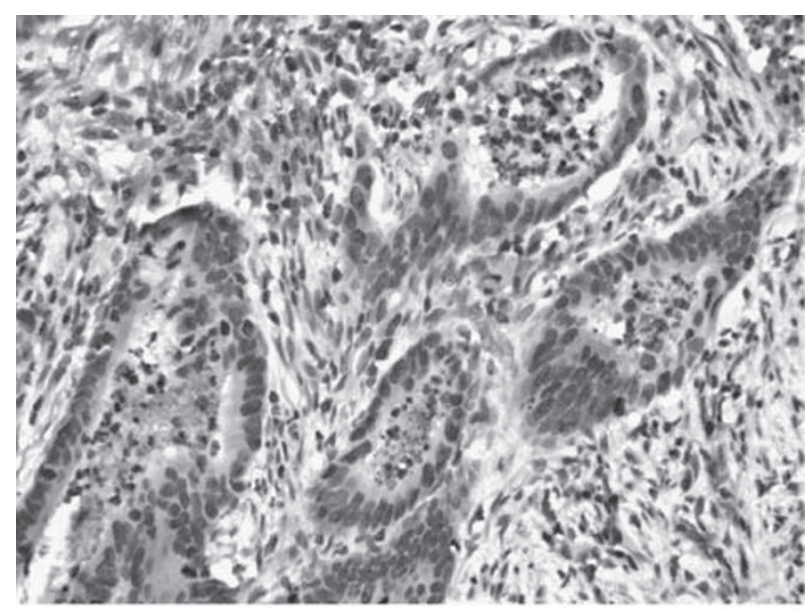

B

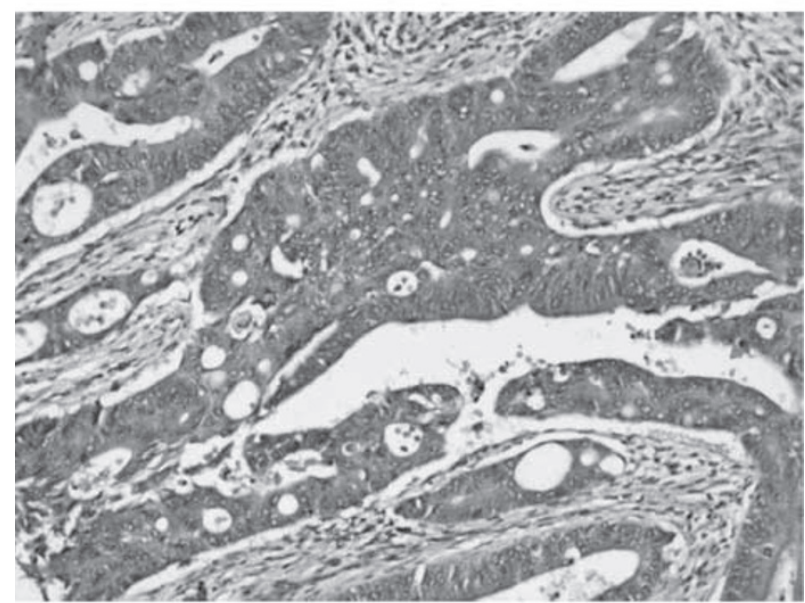

C

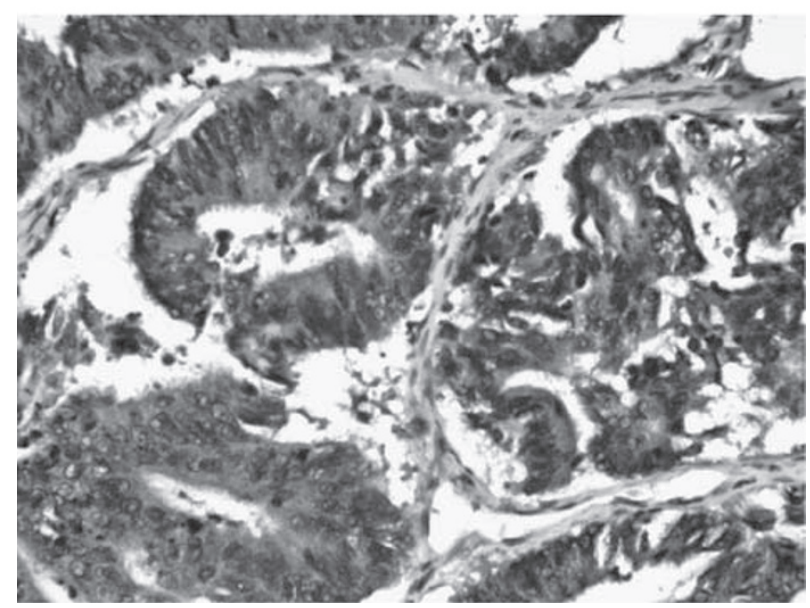

Figure I Representative images showing expression of RUNX3 in the nucleus only $(\mathbf{A})$, in the cytoplasm only $(\mathbf{B})$ and in both the nucleus and cytoplasm $(\mathbf{C})$. Images are at $\times 40$ magnification.

frequent expression of nuclear RUNX3 compared to early stage tumours (Table 1). Kaplan-Meier analysis confirmed that patients with nuclear RUNX3 expression ( $n=631$, Group A) had significantly better survival outcomes $(P=0.025$, logrank test) compared to the relatively small number of patients $(n=79$, Group C) in which RUNX3 expression was restricted to the cytoplasm (Figure 2). This result agrees with observations made in oesophageal cancer and is consistent with current understanding of the role of RUNX3 as a tumour suppressor (Sakakura et al, 
Table I Associations between expression of RUNX3 and clinicopathological and molecular features of CRC

\begin{tabular}{|c|c|c|c|}
\hline \multirow[b]{2}{*}{ Feature $(n)$} & \multicolumn{2}{|c|}{ RUNX3 expression (\%) } & \multirow[b]{2}{*}{$P$} \\
\hline & Any nuclear ${ }^{a}$ & No nuclear ${ }^{b}$ & \\
\hline Total (849) & $631(74)$ & $218(26)$ & \\
\hline \multicolumn{4}{|l|}{ Gender } \\
\hline Male (425) & $316(74)$ & $109(26)$ & \\
\hline Female (424) & $315(74)$ & $109(26)$ & NS \\
\hline \multicolumn{4}{|l|}{ Age } \\
\hline$<71$ years $(429)$ & $313(73)$ & $116(27)$ & \\
\hline$\geqslant 71$ years $(420)$ & $318(76)$ & $102(24)$ & NS \\
\hline \multicolumn{4}{|l|}{ Histological grade } \\
\hline Well differentiated (140) & II | (79) & $29(21)$ & \\
\hline Moderately differentiated (343) & $268(78)$ & $75(22)$ & \\
\hline Poorly differentiated (80) & $62(78)$ & $18(22)$ & NS \\
\hline \multicolumn{4}{|l|}{ Tumour stage } \\
\hline I and I| (535) & $417(78)$ & $118(22)$ & \\
\hline III and IV (3|3) & $214(68)$ & $99(32)$ & 0.002 \\
\hline \multicolumn{4}{|l|}{ Tumour site } \\
\hline Distal (45I) & $348(77)$ & $103(23)$ & \\
\hline Proximal (354) & $254(72)$ & $100(28)$ & 0.079 \\
\hline \multicolumn{4}{|l|}{ Microsatellite instability } \\
\hline Negative (716) & $540(75)$ & $176(25)$ & \\
\hline Positive (87) & $57(66)$ & $30(34)$ & 0.046 \\
\hline
\end{tabular}

$\mathrm{CRC}=$ colorectal cancer; $\mathrm{NS}=$ not significant. ${ }^{\mathrm{a}}$ Any nuclear expression is considered

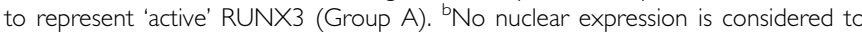
represent 'inactive' RUNX3. This group includes tumours with no nuclear or cytoplasmic expression ( $n=139$, Group B) and tumours with cytoplasmic expression only $(n=79$, Group C).

2007). RUNX3 expression in the cytoplasm has been reported by our group to represent mislocalised and probably inactive protein in gastric and breast cancers (Ito et al, 2005; Lau et al, 2006; Subramaniam et al, 2009). The present results showing that cytoplasmic expression is associated with worse patient outcome support the contention that RUNX3 is in an inactive state.

Interestingly, the subgroup of CRC patients with no or very low expression of RUNX3 in the nucleus or cytoplasm (Group B)

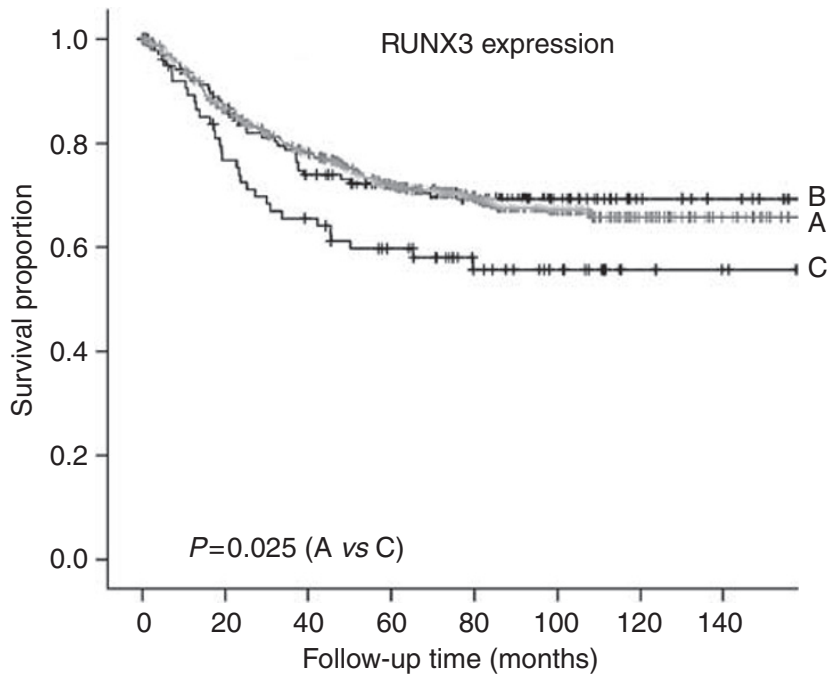

Figure 2 Kaplan-Meier survival analysis for CRC patients according to the expression of RUNX3. (A) Any nuclear expression $(n=631)$; (B) no nuclear or cytoplasmic expression $(n=139)$; (C) cytoplasmic expression only $(n=79)$. Logrank test: $A$ vs $C, P=0.025$.

showed similar prognosis to those with nuclear RUNX3 expression (Group A, Figure 2). This contrasts with several other cancer types (Araki et al, 2005; Wei et al, 2005; Sakakura et al, 2007) and suggests that the presence or absence of RUNX3 may play a lesser role to its cytoplasmic localisation in determining clinical phenotype in CRC. It should be highlighted, however, that two of the earlier studies did not distinguish between nuclear and cytoplasmic staining (Araki et al, 2005; Wei et al, 2005).

In summary, the major findings of this study were that nuclear RUNX3 expression was reduced in advanced stages of CRC and that exclusively cytoplasmic expression of RUNX3 was associated with worse patient outcome.

\section{ACKNOWLEDGEMENTS}

This study was supported by the Singapore Cancer Syndicate (SCS no. BU51).

\section{REFERENCES}

Araki K, Osaki M, Nagahama Y, Hiramatsu T, Nakamura H, Ohgi S, Ito H (2005) Expression of RUNX3 protein in human lung adenocarcinoma: implications for tumour progression and prognosis. Cancer Sci 96: $227-231$

Chai SM, Zeps N, Shearwood AM, Grieu F, Charles A, Harvey J, Goldblatt J, Joseph D, Iacopetta B (2004) Screening for defective DNA mismatch repair in stage II and III colorectal cancer patients. Clin Gastroenterol Hepatol 2: $1017-1025$

Fujii S, Ito K, Ito Y, Ochiai A (2008) Enhancer of zeste homologue 2 (EZH2) down-regulates RUNX3 by increasing histone H3 methylation. J Biol Chem 283: $17324-17332$

Goel A, Arnold CN, Tassone P, Chang DK, Niedzwiecki D, Dowell JM, Wasserman L, Compton C, Mayer RJ, Bertagnolli M, Boland CR (2004) Epigenetic inactivation of RUNX3 in microsatellite unstable sporadic colon cancers. Int J Cancer 112: 754-759

Ito K, Liu Q, Salto-Tellez M, Yano T, Tada K, Ida H, Huang C, Shah N, Inoue $\mathrm{M}$, Rajnakova $\mathrm{A}$, Hiong $\mathrm{KC}$, Peh $\mathrm{BK}$, Han $\mathrm{HC}$, Ito $\mathrm{T}$, Teh $\mathrm{M}$, Yeoh KG, Ito Y (2005) RUNX3, a novel tumour suppressor, is frequently inactivated in gastric cancer by protein mislocalization. Cancer Res 65: $7743-7750$

Ito K, Lim AC, Salto-Tellez M, Motoda L, Osato M, Chuang LS, Lee CW, Voon DC, Koo JK, Wang H, Fukamachi H, Ito Y (2008) RUNX3 attenuates $\beta$-catenin/T cell factors in intestinal tumourigenesis. Cancer Cell 14: $226-237$

Ito Y (2008) RUNX genes in development and cancer: regulation of viral gene expression and the discovery of RUNX family genes. Adv Cancer Res 99: $33-76$

Ito Y, Miyazono K (2003) RUNX transcription factors as key targets of TGF- $\beta$ superfamily signaling. Curr Opin Genet Dev 13: $43-47$

Kim TY, Lee HJ, Hwang KS, Lee M, Kim JW, Bang YJ, Kang GH (2004) Methylation of RUNX3 in various types of human cancers and premalignant stages of gastric carcinoma. Lab Invest 84: 479-484

Kim WJ, Kim EJ, Jeong P, Quan C, Kim J, Li QL, Yang JO, Ito Y, Bae SC (2005) RUNX3 inactivation by point mutations and aberrant DNA methylation in bladder tumours. Cancer Res 65: 9347-9354

$\mathrm{Ku}$ JL, Kang SB, Shin YK, Kang HC, Hong SH, Kim IJ, Shin JH, Han IO, Park JG (2004) Promoter hypermethylation downregulates RUNX3 gene expression in colorectal cancer cell lines. Oncogene 23: 6736-6742

Lau QC, Raja E, Salto-Tellez M, Liu Q, Ito K, Inoue M, Putti TC, Loh M, Ko TK, Huang C, Bhalla KN, Zhu T, Ito Y, Sukumar S (2006) RUNX3 is 
frequently inactivated by dual mechanisms of protein mislocalization and promoter hypermethylation in breast cancer. Cancer Res 66: 6512-6520

Li QL, Ito K, Sakakura C, Fukamachi H, Inoue K, Chi XZ, Lee KY, Nomura S, Lee CW, Han SB, Kim HM, Kim WJ, Yamamoto H, Yamashita N, Yano $\mathrm{T}$, Ikeda $\mathrm{T}$, Itohara $\mathrm{S}$, Inazawa J, Abe T, Hagiwara A, Yamagishi $\mathrm{H}$, Ooe A, Kaneda A, Sugimura T, Ushijima T, Bae SC, Ito Y (2002) Causal relationship between the loss of RUNX3 expression and gastric cancer. Cell 109: $113-124$

Ogino S, Kawasaki T, Kirkner GJ, Kraft P, Loda M, Fuchs CS (2007) Evaluation of markers for $\mathrm{CpG}$ island methylator phenotype (CIMP) in colorectal cancer by a large population-based sample. J Mol Diagn 9: $305-314$

Sakakura C, Miyagawa K, Fukuda KI, Nakashima S, Yoshikawa T, Kin S, Nakase Y, Ida H, Yazumi S, Yamagishi H, Okanoue T, Chiba T, Ito K, Hagiwara A, Ito Y (2007) Frequent silencing of RUNX3 in esophageal squamous cell carcinomas is associated with radioresistance and poor prognosis. Oncogene 26: 5927 - 5938

Subramaniam MM, Chan JY, Soong R, Ito K, Ito Y, Yeoh KG, Salto-Tellez M, Putti TC (2009) RUNX3 inactivation by frequent promoter hypermethylation and protein mislocalization constitute an early event in breast cancer progression. Breast Cancer Res Treat 113: 113-121

Waki T, Tamura G, Sato M, Terashima M, Nishizuka S, Motoyama T (2003) Promoter methylation status of DAP-kinase and RUNX3 genes in neoplastic and non-neoplastic gastric epithelia. Cancer Sci 94: $360-364$

Wei D, Gong W, Oh SC, Li Q, Kim WD, Wang L, Le X, Yao J, Wu TT, Huang S, Xie K (2005) Loss of RUNX3 expression significantly affects the clinical outcome of gastric cancer patients and its restoration causes drastic suppression of tumour growth and metastasis. Cancer Res 65: 4809-4816

Weisenberger DJ, Siegmund KD, Campan M, Young J, Long TI, Faasse MA, Kang GH, Widschwendter M, Weener D, Buchanan D, Koh H, Simms L, Barker M, Leggett B, Levine J, Kim M, French AJ, Thibodeau SN, Jass J, Haile R, Laird PW (2006) CpG island methylator phenotype underlies sporadic microsatellite instability and is tightly associated with BRAF mutation in colorectal cancer. Nat Genet 38: 787-793

$\mathrm{Xu} \mathrm{Y}$, Pasche B (2007) TGF- $\beta$ signaling alterations and susceptibility to colorectal cancer. Hum Molec Gen 16: R14-R20 